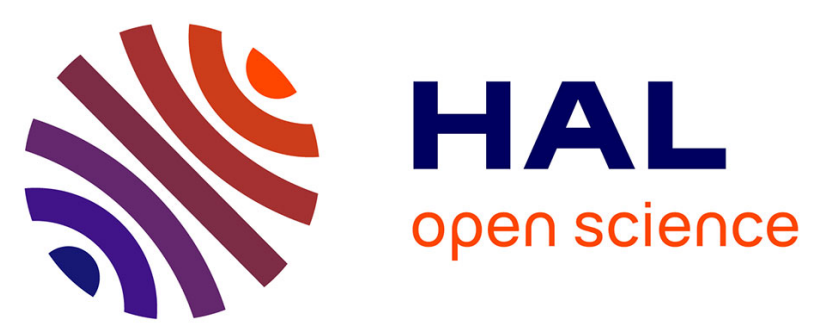

\title{
Short-term profiles of plasma gonadotropin and estradiol-17 $\beta$ levels in the female rainbow trout, from early ovarian recrudescence and throughout vitellogenesis
}

Yonathan Zohar, Bernard Breton, Alexis Fostier

\section{To cite this version:}

Yonathan Zohar, Bernard Breton, Alexis Fostier. Short-term profiles of plasma gonadotropin and estradiol-17 $\beta$ levels in the female rainbow trout, from early ovarian recrudescence and throughout vitellogenesis. General and Comparative Endocrinology, 1986, 64 (2), pp.172-188. 10.1016/00166480(86)90002-X . hal-01600969

\section{HAL Id: hal-01600969 \\ https://hal.science/hal-01600969}

Submitted on 2 Jun 2020

HAL is a multi-disciplinary open access archive for the deposit and dissemination of scientific research documents, whether they are published or not. The documents may come from teaching and research institutions in France or abroad, or from public or private research centers.
L'archive ouverte pluridisciplinaire HAL, est destinée au dépôt et à la diffusion de documents scientifiques de niveau recherche, publiés ou non, émanant des établissements d'enseignement et de recherche français ou étrangers, des laboratoires publics ou privés.

\section{다(1)(2)}

Distributed under a Creative Commons Attribution - ShareAlikel 4.0 International 


\title{
Short-Term Profiles of Plasma Gonadotropin and Estradiol-17 $\beta$ Levels in the Female Rainbow Trout, from Early Ovarian Recrudescence and throughout Vitellogenesis
}

\author{
Y. ZOHAR, ${ }^{1}$ B. BrETON, AND A. FoSTIER \\ Laboratoire de Physiologie de Poissons, INRA, Campus de Beaulieu, 35042 Rennes, France
}

Acceptcd May 12, 1986

\begin{abstract}
At various stages throughout the annual reproductive cycle, female rainbow trout (Salmo gairdneri) were fitted with a catheter in the dorsal aorta. They were bled via the catheter at frequencies of once every 30,60 , or 240 min over periods of 5 to $24 \mathrm{hr}$. Gonadotropin $(\mathrm{GtH})$, estradiol-17ß $\left(E_{2} 17 \beta\right)$, and estrone levels were measured in the plasma samples. At early ovarian recrudescence (March), short-term (1-2 hr), high-amplitude ( $\Delta \mathrm{GtH}=$ up to 100 $\mathrm{ng} / \mathrm{ml}$ ), episodic pulses of $\mathrm{GtH}$ were recorded in the plasma of 12 of the 26 studied fish. In the others, GtH levels remained low and constant. No synchronization was found among the individual $\mathrm{GtH}$ profiles. $E_{2} 17 \beta$ levels in the same fish were low and constant while estrone was not detectable. At early stages of exogenous vitellogenesis (June), plasma GtH $(1-3 \mathrm{ng} / \mathrm{ml})$ and $E_{2} 17 \beta(0.5-1.5 \mathrm{ng} / \mathrm{ml})$ levels were low and constant. At advanced stages of exogenous vitellogenesis (September-October), fluctuating $\mathrm{GtH}$ levels were found again in most of the females; basal GtH concentrations were only slightly higher than those recorded in June. The fluctuations consisted of short-term (1-3 hr) random GtH pulses of moderate amplitude ( $\Delta \mathrm{GtH}=$ up to $5 \mathrm{ng} / \mathrm{ml}$ ), occurring at a relatively high frequency (up to 5 per $12 \mathrm{hr}$ ). Although no regular synchronous daily pattern of GtH was noted, most of the GtH pulses were observed during the photophase and early scotophase. The appearance of GtH pulsatility during exogenous vitellogenesis was accompanied by a large increase in plasma $E_{2} 17 \beta$ up to levels ranging from 6 to $30 \mathrm{ng} / \mathrm{ml}$. In contrast to the $\mathrm{GtH}$ profiles, the $\mathrm{E}_{2} 17 \beta$ profiles showed continuous and progressive variations, superimposed on the abrupt GtH pulses, and a high degree of synchronization. $\mathrm{E}_{2} 17 \beta$ levels increased during the photophase and reached maxima toward and during early scotophase. 1986 Academic Press, Inc.
\end{abstract}

The seasonal variations in plasma gonadotropin $(\mathrm{GtH})$ and sex-steroid levels were thoroughly studied in the female trout (Salmo gairdneri). A careful examination of the various studies reveals some discrepancies amongst them. A transient increase in $\mathrm{GtH}$ levels has been observed by some authors at early stages of ovarian development (spring) in the rainbow (Breton et al., 1985) and brown (Billard et al., 1978; Breton et al., 1983) trout, whereas others have reported constant or only slightly varying levels of the hormone (rainbow

\footnotetext{
1 Present address for reprint requests: National Center for Mariculture, Israel Oceanographic and Limnological Research Institute, P.O. Box 1212, 88112 Elat, Israel.
}

trout: Scott and Sumpter, 1983; Sumpter $e t$ al., 1984). At the same time, estradiol-17 $\beta$ $\left(\mathrm{E}_{2} 17 \beta\right)$ levels have been reported as low and constant (rainbow trout: Lambert et al., 1978; Whitehead et al., 1978a, b; Scott et al., 1980; Van Bohemen and Lambert, 1981) or increasing steadily (brown trout: Billard et al., 1978; Breton et al., 1983; rainbow trout: Sumpter et al., 1984). During vitellogenesis plasma GtH levels have been reported as either (a) increasing moderately (brown trout: Breton et al., 1983; Billard et al., 1978; Crim and Idler, 1978), (b) remaining constant (rainbow trout: Scott and Sumpter, 1983), or (c) initially increasing and then declining continuously (rainbow trout: Bromage et al., 1982a, b; Whitehead et al., 1983). Plasma 
levels of $E_{2} 17 \beta$ and testosterone rise considerably during vitellogenesis and decline progressively from its final stages (brown trout: Rillard et al., 1978; Breton et al., 1983; rainbow trout: Fostier et al., 1978; Scott and Sumpter, 1983; Scott et al., 1980; Bromage et al., 1982a, b).

One possible explanation for the abovementioned discrepancies might be the fact that the long term (seasonal) profiles only partially reflect the hormonal function. In fact, in the majority of the mammalian species studied in this respect, the fundamental signals composing the hormonal message are generally of very short duration, i.e., from a few minutes up to a few hours (see review in Knobil, 1980; Lincoln and Short, 1980; Brinkley, 1981; Desjardins, 1981). Similarly, daily variations in the circulating levels of the reproductive hormones have been reported in different fish species. Daily cycles in plasma $\mathrm{GtH}$ levels have been demonstrated in the $\mathrm{fe}$ male goldfish, Carassius auratus (Breton et al., 1972; Hontela and Peter, 1978, 1980a; Vodicnik et al., 1978; Gillet and Billard, 1981; Gillet et al., 1981) and in the male and female of the common carp, Cyprinus carpio; the silver carp, Hypophthalmichthys molitrix; and the grass carp, Ctenopharyngodon idellus (Pan et al., 1980). Circulating levels of testosterone, $\mathrm{E}_{2} 17 \beta$, and estrone have been shown to fluctuate during the day in the catfish, Heteropneustes fossilis (Lamba et al., 1983). In salmonids, data on circadian changes in the levels of reproductive hormones are rare. Our previous reports (Zohar, 1980; Zohar et al., 1982a) have presented some data showing that in the female rainbow trout, daily (short-term) fluctuations in plasma $\mathrm{GtH}$ levels do occur and are superimposed on the seasonal variations of the hormone.

The aim of the present work was to study, at some characteristic stages of the reproductive cycle of the female rainbow trout, the short-term (circadian and ultra- dian) profiles of plasma GtH and main sexsteroid levels. Since our previous data (Zohar, 1980; Zohar et al., 1982a) had indicated a lack of synchronization between fish in the GtH secretion pattern, we studied hormonal profiles of individual free-swimming trout, fitted with a catheter in the dorsal aorta. The present paper describes short-term profiles of $\mathrm{GtH}$ and $E_{2} 17 \beta$ from early ovarian recrudescence and throughout vitellogenesis, whereas our following one (Zohar et al., 1986) describes short-term profiles of $\mathrm{GtH}$ and $17 \alpha-h y$ droxy, 20ß-dihydroprogesterone at the periovulatory period.

\section{MATERIALS AND METHODS}

\section{(a) Animals and Stocking Conditions}

Female trout, aged 3 to 4 years and weighing 1.5 to 3 $\mathrm{kg}$, were used in the present study. All of them had reached sexual maturity at least once before. About 2 to 3 months before the beginning of the acclimation to experimental conditions, fish were transferred from farm to indoor tanks supplied with recycled water. Then, 3 to 4 weeks before the initiation of the experiments the fish were transferred into tanks $(70-150$ liters) in which they were kept individually. Fish were exposed to a natural photoperiod. Water temperature was maintained at $10 \pm 2^{\circ}$ between December and May and at $15 \pm 2^{\circ}$ between June and November. Fish were fed with artificial food granules at a daily ratio of $1 \%$ of their body weight. Feeding time was between 1000 and $1200 \mathrm{hr}$.

\section{(b) Dorsal Aorta Catheterization}

At various times of each year over a 3-year period, catheters were implanted in the dorsal aortas of 10-20 female trout. Only fish which had showed active feeding behavior for at least 1 week were catheterized. The procedure for implanting a catheter in the dorsal aorta has been described in detail by Zohar (1980). The same study (Lohar, 1980) and Bry and Zohar (1980) showed that the resumption of normal feeding behavior after catheterization reflected the recovery of fish from the stress situation related to the surgery. In such fish, the surgery and the presence of the catheter in the dorsal aorta did not affect gonadotropin levels in the blood or ovarian function (Zohar, 1980).

\section{(c) Blood Sampling}

Before catheterization, $0.3-0.5 \mathrm{ml}$ of blood was removed from the caudal vasculature of every fish. Hor- 
mone levels in these samples were compared to those recorded in blood sampled successively via the dorsal aortic catheter during experimentation, as described by Zohar (1980). After catheterization, fish were allowed to recover for at least 3 days before further bleeding.

In agreement with our previous findings (Zohar, 1980; Bry and Zohar, 1980), only fish which resumed normal feeding behavior after surgery were selected for experimentation. Individual free-swimming catheterized trout werc blcd repeatedly via the catheter at frequencies of once ever $1 / 2,1$, or 4 hr over periods of 5 to $24 \mathrm{hr}$. In order to bleed the fish, the cannula, its stopper (a scaled syringe needle), and its cork floater were gently removed from the water. The cannula was unplugged and fitted with a $1-\mathrm{ml}$ syringe. A volume of $250 \mu \mathrm{l}$, corresponding to $50 \mu \mathrm{l}$ more than the dead volume of the catheter, was removed and discarded. The cannula tip was then fitted with a clean 1-ml syringe previously rinsed with lithium heparinate solution (100-150 iu of heparine in $0.7 \%$ of saline). A volume of 300 to $400 \mu \mathrm{l}$ of blood was withdrawn and transferred to ice-cold 3-ml tubes. At the end of each sampling, the blood filling the catheter was pushed back by $200 \mu \mathrm{l}$ of lithium-heparinate saline solution (as above) and the cannula was plugged. Bleeding during the dark period was made using a dim red light to which wavelength salmonids adapted to dark are not sensitive (IIanyu and Tamura, 1978). Blood samples were centrifuged $\left(15 \mathrm{~min}\right.$ at $5000 \mathrm{rpm}$ and at $\left.4^{\circ}\right)$, and the plasma was stored at $-30^{\circ}$ until further analysis.

\section{(d) Determination of Ovarian Developmental Stages}

At the end of each experiment, the females were sacrificed and their ovaries submitted to histological analysis. We distinguished three major ovarian developmental stages (based on Van den Hurk and Peute, 1979):

1. Early ovarian recrudescence (March). Ovaries contained isolated or grouped oogonia, oogonia undergoing mitotic divisions, oocytes at different stages of the prophase of the first meiotic division, and different proportions of oocytes undergoinng previtellogenic growth, endogenous vitellogenesis, and the very beginnings of exogenous vitellogenesis. Previtellogenic oocytes ( 50 and $500 \mu \mathrm{m}$ in diameter) were characterized by the presence of Balbiany bodies. Their nuclei were relatively big and many nucleoli were scattered at its periphery. Their follicular layers were not completely organized. Oocytes which undergo endogenous vitellogenesis $(400-900 \mu \mathrm{m}$ in diameter) were characterized by the successive appearance of two structures: the vitellin vesicles (the future cortical alveoli) which appeared first in the ooplasm periphery and spread later toward its center, and the lipid globules which appeared in the perinuclear area, fused, and gained size. The zona radiata and the follicular layers were already organized in such oocytes. Oocytes undergoing early exogenous vitellogenesis are described below.

2. Early exogenous vitellogenesis (June). Ovaries contained mainly oocytes undergoing initial stages of exogenous vitellogenesis. Such oocytes (which measured 1 to $2 \mathrm{~mm}$ in diameter) were characterized by the progressive appearance, in the periphery of the ooplasm, of vitellin granules.

3. Advanced exogenous vitellogenesis (September-October). Ovaries contained mainly vitellogenic oocytes with diameters of up to $4-5 \mathrm{~mm}$. They were characterized by the massive appearance of vitellin granules all over the ooplasm. These granules coalesce to form spheric structures (vitellin spheres) which occupy most of the oocyte volume.

\section{(e) Hormone Measurements}

Gonadotropin was measured by radioimmunoassay (RIA) according to Breton and Billard (1977). The antibody used was anti-trout $\mathrm{GtH}$ at a final dilution of 1:130,000 to 1:200,000. A highly purified salmon GtH (Breton et al., 1978) was used for the standard curve and for the radioactive labeling. Each unknown sample was measured in triplicate. All samples from a single experiment were measured in the same RIA run. GtH concentration in most of the samples was measured twice, in two different RIA runs, in order to confirm the existence of fluctuations in the hormonal concentration and to eliminate any error due to the measuring technique (see also Zohar, 1980).

The sensitivity of the RIA varied between 15 and 30 pg GtH per tube which corresponds to 0.3 and $0.6 \mathrm{ng}$ $\mathrm{GtH} / \mathrm{ml}$ of plasma. The intraassay variability (Table 1) was estimated by repetitive measurements, in each of the RIA runs, of the GtH concentrations in different pools of plasma. These pools were sampled from fish at different physiological stages and contained various $\mathrm{GtH}$ levels, covering the entire range of the standard curve.

The radioimmunoassays of estradiol-17 $\beta$ and estrone were carried out according to Fostier et al. (1978), except that bound steroid was precipitated with polyethylene glycol (Fostier et al., 1982). Both steroids were measured after being extracted from the plasma and separated from each other on an LH-20 column. Unknown samples were measured in triplicate. The estradiol-17 $\beta$ antibody was used at a final dilution of 1:50,000, and its degree of cross-reactivity with other steroids was $11 \%$ for estrone, $9 \%$ for 16 -ketoestradiol-17 $\beta, 8 \%$ for 16-epiestriol, and less than $0.5 \%$ for estriol, estradiol-17 $\alpha$, testosterone, 11-ketotestosterone, and $17 \alpha$-hydroxy,20ß-dihydroprogesterone. The estrone antibody was used at a final dilution of 1:4800, and its degree of cross-reactivity was less than $0.8 \%$ for estradiol-17 $\beta$, estriol, testosterone, 
TABLE 1

THE INTRAASSAY VARIABILITY OF THE RADIOIMMUNOASSAYS

\begin{tabular}{lccccc}
\hline Hormonc & $\begin{array}{c}\text { Level } \\
(\mathrm{ng} / \mathrm{mL})\end{array}$ & $\begin{array}{c}\text { Mean } \\
\text { CV }(\%)\end{array}$ & $\begin{array}{c}\text { Range of } \\
\text { CV }(\%)\end{array}$ & $\begin{array}{c}\text { Number of } \\
\text { samples/assay }\end{array}$ & $\begin{array}{c}\text { Number of } \\
\text { assays }\end{array}$ \\
\hline GtH & $1-3$ & 9.3 & $6.0-10.9$ & $5-7$ & 7 \\
& $4-6$ & 7.7 & $4.1-12.3$ & $5-7$ & 7 \\
& $7-12$ & 9.9 & $7.3-11.9$ & $5-7$ & 8 \\
& $14-20$ & 6.6 & $4.0-9.9$ & $5-7$ & 5 \\
Estradiol 173 & $40-50$ & 6.8 & $2.3-8.8$ & $5-6$ & 5 \\
& $105-125$ & 4.9 & $3.6-6.9$ & $5-7$ & 3 \\
& $1-2$ & 9.6 & $6.3-12.4$ & 6 & 3 \\
Estrone & $3-4$ & 5.3 & $2.6-8.7$ & 5 & 2 \\
\hline
\end{tabular}

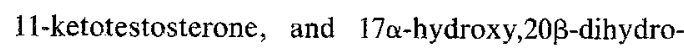
progesterone. The sensitivity of both radioimmunoassays was approximately $10 \mathrm{pg} /$ tube, and the intraassay variability is given in Table 1 .

\section{(f) Analytical Methods}

The mean, coefficient of variation (CV) and variance were calculated for all the values composing each of the individual hormonal profiles. A second (hypothetical) variance was calculated for each profile, based on the highest $\mathrm{CV}$ obtained for a plasma pool (Table 1) having a hormonc concentration close to the mean of the values composing the tested profile. This hypothetical variance (and CV) is thus the expected one, supposing that the observed hormonal fluctuations reflected only the variations of the RIA. The real and hypothetical variances were compared by $x^{2}$ test. On the basis of this comparison, all profiles having a real $\mathrm{CV}$ at least twice as large as the hypothetical one were considered as fluctuating significantly, due to physiological rcasons. These fluctuating profiles showed a highly significant $(P<0.005)$ larger real $\mathrm{CV}$ than a hypothetical one. For the nonfluctuating profilcs (real CV $\leqq 2 \times$ hypothetical $\mathrm{CV}$ ), the mean of all values composing each of them was considered as the "basal level."

We distinguished two types of fluctuating profiles: (1).Irregular profiles, showing random, episodic fluctuations of hormonal levels. In this group there was no synchronization between individual profiles of animals representing the same physiological stage; (2) Regular profiles, showing gradual and continuous changes in the hormonal levels. In this group therc was a certain synchronization between profiles of individual animals. The two types of profiles were further analyzed by different methods.

(I) Irregular profiles. The hormonal concentrations composing each of the profiles were divided into two subgroups. The first one included the low concentra- tions, representing the "baseline" levels or "inliers." The second subgroup included the high hormonal concentrations, representing "pulsation" levels or "outliers." The statistical detection of outliers was affected according to tests adapted for one (Dixon, 1953) or many (Grubbs, 1969) outliers. High hormonal levels which were characterized as "outliers" were then eliminated one by one, and the fluctuating nature of the resting values of the profile was tested each time as described above. This analysis was stopped when the $\mathrm{CV}$ of the resting values ("inliers") became equal to or smaller than twice the hypothetical $\mathrm{CV}$.

(2) Regular profiles. A global analysis of the profiles of all the animals representing a given ovarian developmental stage was realized by a two-factorial analysis of variance (the two factors analyzed were number of animals and sampling time). When significant differences were found, the analysis was continued by the Duncan test (Bliss, 1967). This enabled the identification of significant differences, during the experimental period, between groups of mean hormonal levels.

\section{RESULTS}

(a) Early Ovarian Recrudescence: March (Figs. 1 and 2)

In trout which were sampled every 4 hr for $24 \mathrm{hr}$, we observed in five of the nine fish studied significant short-term increases in plasma GtH levels (Fig. 1). In two of the females (Nos. 113 and 115), the amplitude of the increases reached around 100 and $50 \mathrm{ng} / \mathrm{ml}$, respectively, whereas in the others the amplitude varied between 4 and $8 \mathrm{ng} / \mathrm{ml}$. No synchronization was observed among the individual profiles. In 


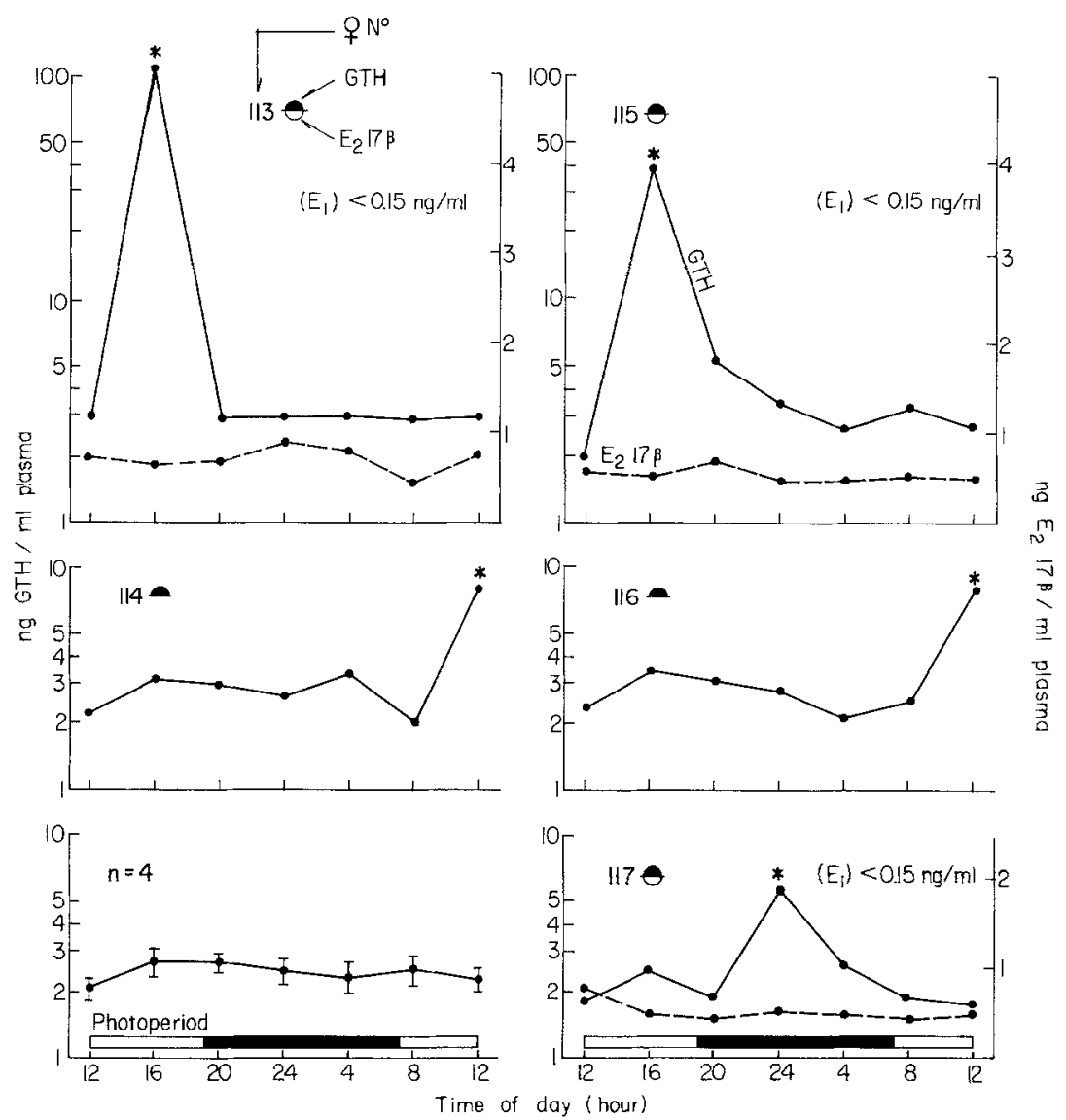

FIG. 1. Profiles of plasma levels of GtH (continuous lines) and $\mathrm{E}_{2} 17 \beta$ (broken lines) in female trout at early ovarian recrudescence (March). Females were bled every $4 \mathrm{hr}$ over a period of $24 \mathrm{hr}$. Individual GtH profiles with significant fluctuations in hormone levels, and the mean of profiles ( $n=4$ fish) with stable GtH levels, are presented. The number of each female is indicated. The statistical significance of the hormonal fluctuations is indicated by the following symbols: for $\mathrm{GtH}, \boldsymbol{\Omega}=$ nonsignificant and $\boldsymbol{\Omega}=$ significant; for $\mathrm{E}_{2} 17 \beta, \boldsymbol{\nabla}$ - nonsignificant and $\boldsymbol{\sigma}=$ significant. The symbol * situated above a peak indicates that it is significantly higher than the basal level.

four females, GtH levels remained constant. Four of the GtH peaks were observed in the middle or toward the end of the photophase, whereas another peak occurred during the scotophase. In the fish in which they were measured, estradiol-17 $\beta$ levels were found to be low and constant, whereas estrone levels were below the detection limits of the RIA $(0.15 \mathrm{ng} / \mathrm{ml})$.

Bleeding fish every hour for $12 \mathrm{hr}$, during the day (for one group) or throughout the night (for another), showed short-term increases (pulses) in plasma GtH levels in seven of the 17 sampled females (Fig. 2). In the other fish, GtH levels remained con- stant. The amplitude of the GtH increases was relatively large in some of the cases, and ranged from 5 to about $100 \mathrm{ng} / \mathrm{ml}$. In most of the females, a GtH pulse included only one point (sample) after which $\mathrm{GtH}$ returned to its basal level within $1 \mathrm{hr}$. In one female (No. 122), in which the GtH peak value was the highest $(118 \mathrm{ng} / \mathrm{ml})$, GtH returned to its basal level more gradually, through an intermediate value observed $1 \mathrm{~h}$ after the peak.

Although no synchronization was evident among individual profiles, six of eight significant GtH pulses occurred during the night, whereas the others occurred in the 


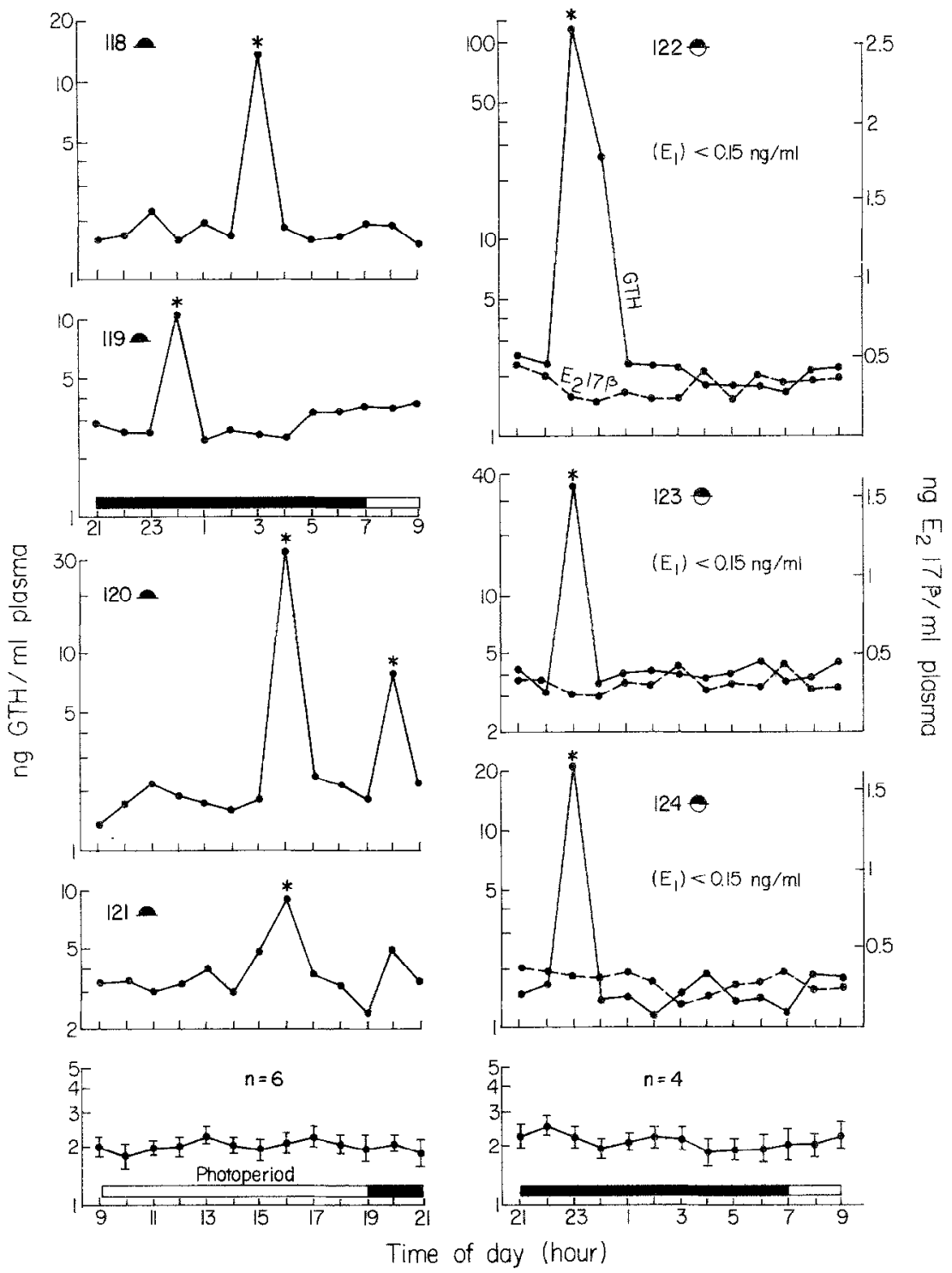

Frg. 2. Profiles of plasma levels of $\mathrm{GtH}$ (continuous lines) and $\mathrm{E}_{2} 17 \beta$ (broken lines) in female trout at early ovarian recrudescence (March). Females were bled every hour over a period of 12 hr, one group from 0900 to $2100 \mathrm{hr}$ and a second group from 2100 to $0900 \mathrm{hr}$. For other details, see the legend of Fig. 1.

late photophase (Fig. 2). In all the fish exhibiting GtH pulses, only one pulse was detected throughout the 12-hr sampling period, with the exception of one female, for which we observed two significant $\mathrm{GtH}$ elevations. In three females showing GtH pulses, we measured low and constant $\mathrm{E}_{2} 17 \beta$ levels, whereas estrone was not detectable (Fig. 2, female Nos. 122-124). (b) Early Exogenous Vitellogenesis: June (Fig. 3)

At this stage of ovarian development, $\mathrm{GtH}$ levels were low $(1-3 \mathrm{ng} / \mathrm{ml})$ and relatively stable. When females were sampled once every $4 \mathrm{hr}$ for $24 \mathrm{hr}$ (Fig. 3a), we observed slight fluctuations in GtH levels in two of six fish, whereas in the others these 


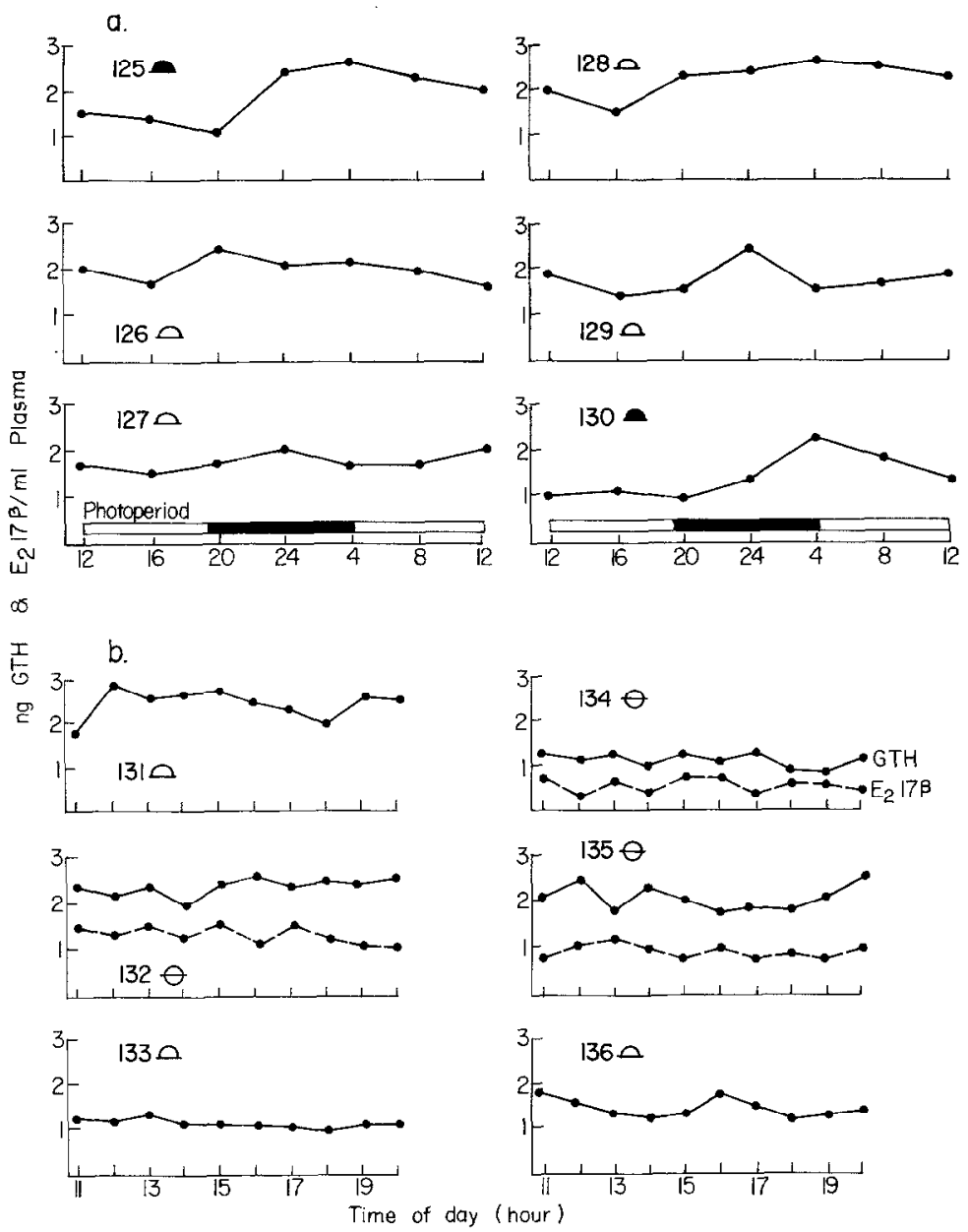

FIG. 3. Individual profiles of plasma levels of GtH (continuous lines) and $E_{2} 17 \beta$ (broken lines) in female trout at early exogenous vitellogenesis (June). Females were bled either every 4 hr over a period of $24 \mathrm{hr}$ (a), or every hour over $9 \mathrm{hr}(\mathrm{b})$. For other details, see the legend of Fig. 1.

levels remained constant. In all females sampled every $1 \mathrm{hr}$ for $10 \mathrm{hr}$ (Fig. 3b), GtH levels were low and stable. When measured, $\mathrm{E}_{2} 17 \beta$ levels were found to be low and constant (Fig. 3b).

\section{(c) Advanced Exogenous Vitellogenesis:} September-October (Figs. 4-7)

Due to space limitations, we include here only a representative number of individual hormonal profiles out of nearly 50 made on fish at this stage of ovarian development.

Of the 47 analyzed individual GtH profiles of females undergoing advanced exogenous vitellogenesis, 29 exhibited significant daily fluctuations.
In Fig. 4 are shown individual GtH profiles of nine fish which were bled hourly for $9 \mathrm{hr}$. For two females (Nos. 145 and 147), two GtH profiles are shown which were determined in two separate RIA runs. Seven of the nine GtH profiles fluctuated significantly. In all these cases, one to two significant $\mathrm{GtH}$ pulses were found during the 9-hr sampling period.

In Fig. 5 are shown individual profiles of $\mathrm{GtH}, \mathrm{E}_{2} 17 \beta$, and estrone in eight females which were bled once every hour for $12 \mathrm{hr}$. Six of the GtH profiles fluctuated significantly, whereas in another one (No. 155) fluctuations were very close to being significant. In four of the females, significant 


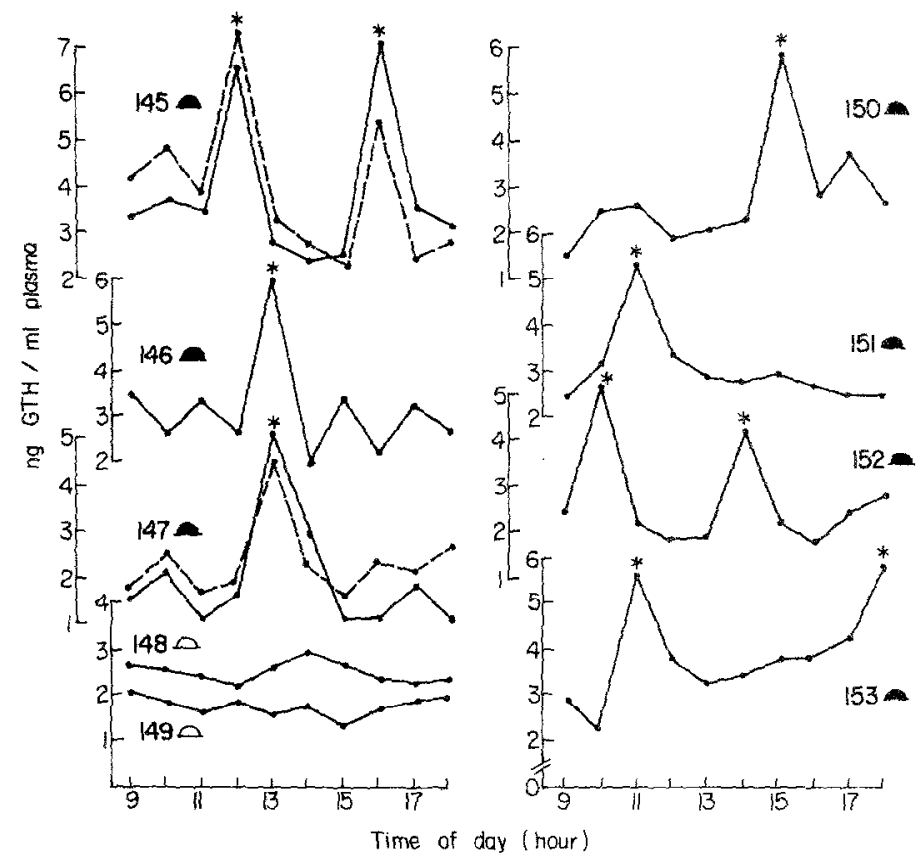

FrG. 4. Individual profiles of plasma GtH levels in female trout at advanced exogenous vitellogenesis (September). Females were bled every hour over a period of $9 \mathrm{hr}$. The two curves in continuous and broken lines correspond, for the same female, to results obtained in two different runs of RIA. For other details, see the legend of Fig. 1.

GtH pulses were recorded, whereas in another (No. 154) a long GtH elevation was observed. In both groups of profiles (Figs. 4 and 5), most of the GtH pulses included only one high GtH value (except in female No. 159).

No synchronization existed among the individual $\mathrm{GtH}$ profiles of fish bled hourly. However, we noted 13 significant GtH pulses in the eight females which were sampled between 0800 and $2000 \mathrm{hr}$ (Fig. 5), and only six signiticant pulses in seven females sampled between 2000 and $0800 \mathrm{hr}$ (individual curves not shown). The lack of synchronization between the individual GtH profiles is reflected by their mean profile (Fig. 6, low curve), which masks the existence of the GtH pulsatility and shows very constant GtH levels over the 24-hr sampling period. Figure 7 shows GtH profiles in eight females sampled once every 30 min for $5 \frac{1}{2}$ hours. In this case, significant fluctuations in $\mathrm{GtH}$ levels occurred in five of the females. Due to the more frequent samplings, most of the elevations in $\mathrm{GtH}$ levels included at least two high GtH values.

The analysis of all $\mathrm{GtH}$ profiles which we recorded showed that when oocytes undergo advanced exogenous vitellogenesis, the dynamics of GtH secretion differs from that found at earlier stages of gonadal development. One to five GtH pulses occur over a period of $12 \mathrm{hr}$; their duration ranges from 1 to $3 \mathrm{hr}$ and their amplitude reaches around $5 \mathrm{ng} / \mathrm{ml}$.

As far as estradiol- $17 \beta$ is concerned, its mean level was much more elevated than at earlier stages of ovarian development (Fig. 6 , Student $t$ test, $P<0.01$ ). The levels of this steroid fluctuated significantly during the day in eight of 11 studied females (Fig: 5 for the profiles of seven females sampled between 0800 and $2000 \mathrm{hr}$ ). The pattern of the individual $E_{2} 17 \beta$ profiles was different from that established for the $\mathrm{GtH} . \mathrm{E}_{2} 17 \beta$ levels did not change abruptly, but revealed continuous, relatively synchronized daily 

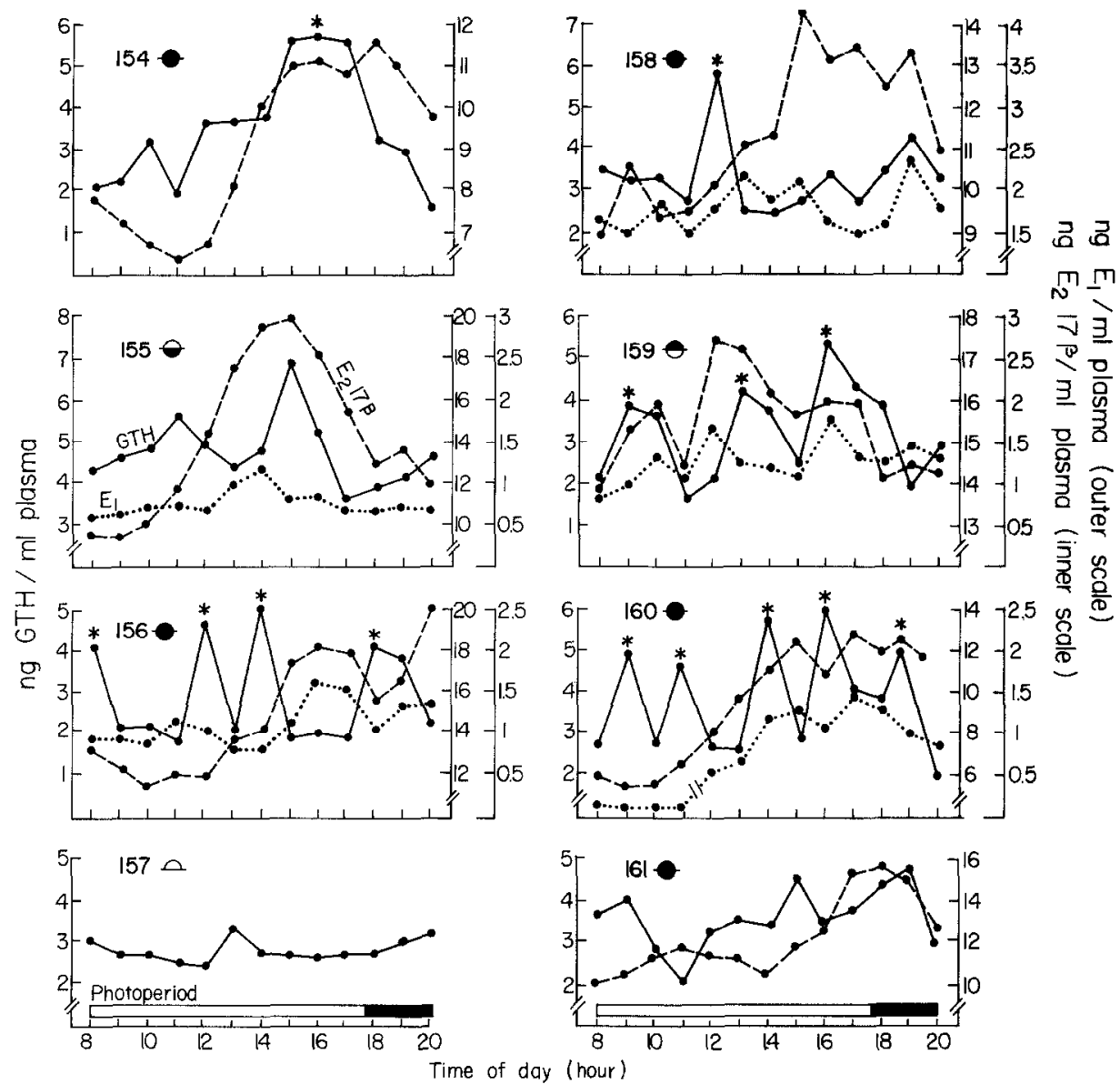

FIG. 5. Individual profiles of plasma levels of $\mathrm{GtH}$ (continuous lines), $\mathrm{E}_{2} 17 \beta$ (broken lines), and estrone (dotted lines) in female trout at advanced exogenous vitellogenesis (October). Females were bled every hour over a period of $12 \mathrm{hr}$. For other details, see the legend of Fig. 1.

variations overriding the GtH pulses (Fig. 5). In the six fish showing fluctuating profiles out of the seven sampled from 0800 to $2000 \mathrm{hr}, \mathrm{E}_{2} 17 \beta$ levels were lower in the first part of the photophase, increased progressively later on, and reached maxima during the later part of the photophase or at the beginning of the scotophase. In some of these females, $E_{2} 17 \beta$ tended to decrease after reaching maxima. This tendency continued in fish sampled hourly between 2000 and $0800 \mathrm{hr}$ (curves not shown). The relative synchronization between the individual $E_{2} 17 \beta$ profiles is reflected in their mean profile (Fig. 6, upper curve), which shows a progressive, highly significant increase of $E_{2} 17 \beta$ during the day, from min- imal levels at 0800 to $1000 \mathrm{hr}$ up to maxima reached between 1500 and $1700 \mathrm{hr}$, followed by an initiation of a decline. Plasma $E_{2} 17 \beta$ profiles were recorded only in four females sampled between 2000 and $0800 \mathrm{hr}$. These profiles (not shown) exhibited relatively high individual variation, and the calculation of their average was thus meaningless. More fish should be studied in order to confirm the $\mathrm{E}_{2} 17 \beta$ pattern during the nocturnal part of the $24 \mathrm{hr}$.

We measured estrone levels in five females (Fig. 5). Those levels were very low, close to the detection limit of the RIA. In some of the females (Nos. 156 and 160), the estrone profiles were parallel to those of $\mathrm{E}_{2} 17 \beta$. 

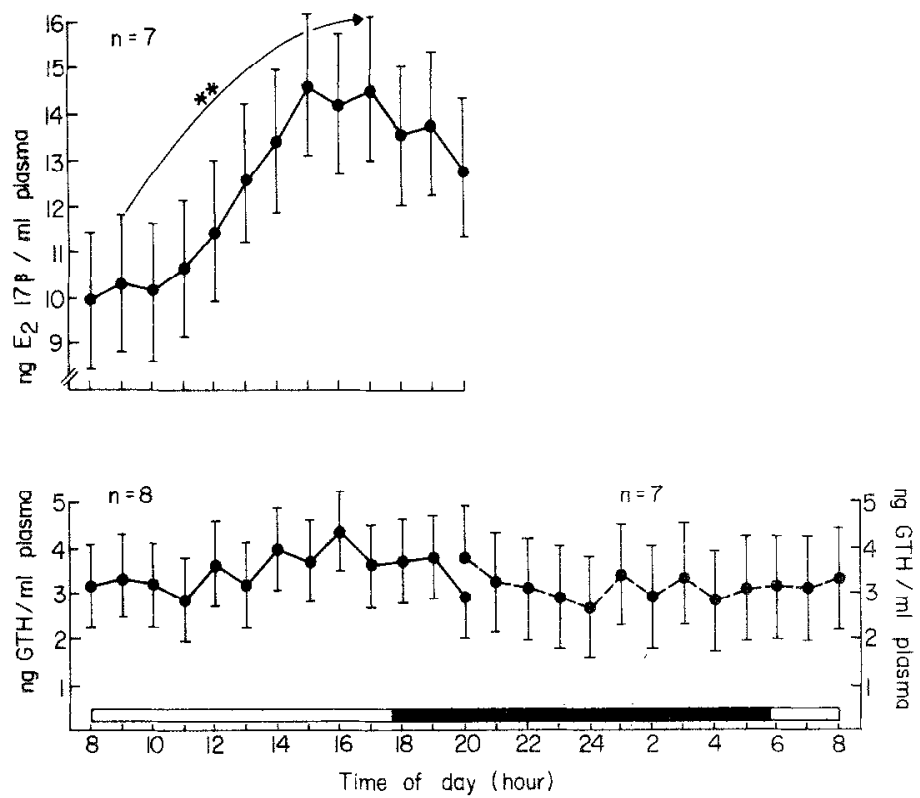

FIG. 6. Mean profiles $\left(x \pm \mathrm{tSE}\right.$ ) of plasma levels of GtH (lower curves-24 hr) and of $\mathrm{E}_{2} 17 \beta$ (upper curve $-12 \mathrm{hr}$ ) in female trout at advanced exogenous vitellogenesis (October). The mean profiles were established from individual profiles of fish sampled every hour over a period of $12 \mathrm{hr}$ (Fig. 5 for the group sampled from 0900 to $2100 \mathrm{hr}) .{ }^{*}$ Significantly different at $P<0.01$.

\section{DISCUSSION}

Annual changes in GtH levels in the female rainbow trout have been described previously (see introduction). The present study together with our following one (Zohar et al., 1986) reveal that in addition to the seasonal variations in the hormone concentration, important modifications occur in the pattern of the short-term profiles of GtH levels throughout oocyte development.

A transient GtH elevation has previously been observed in the circulation of the female rainbow and brown trout undergoing ovarian recrudescence. This elevation occurred either in spring (March) in fish exposed to rlatural photoperiodic regime (Billard et al., 1978; Breton et al., 1983), or earlier (between January and March) when the photoperiodic regime was altered (Breton et al., 1985). Our present data suggest that this increase in $\mathrm{GtH}$ is the reflection of short-term, high-amplitude, episodic elevations in the hormone level. The GtH pulses observed in March were not synchronized among the individual fish and high GtH levels were recorded during no more than $2 \mathrm{hr}$. Thus, a point sampling of a group of fish undergoing early ovarian recrudescence (March), for the study of seasonal GtH variations, might show a mean elevated GtH level accompanied by high individual variation, as was actually the case (Breton et al., 1983, 1985).

High-amplitude GtH pulses were observed in only $50 \%$ of the fish studied in March. This might be due to the short duration of the pulses and to their low frequency (in most of the cases only one GtH pulse was observed during the 12-hr sampling period). However, the absence of GtH pulses in half of the females should also be considered together with the fact that in June no more such GtH pulses were observed, and with the findings of Breton et al. $(1983,1985)$ concerning the transient nature of the spring GtH surge. Such a con- 


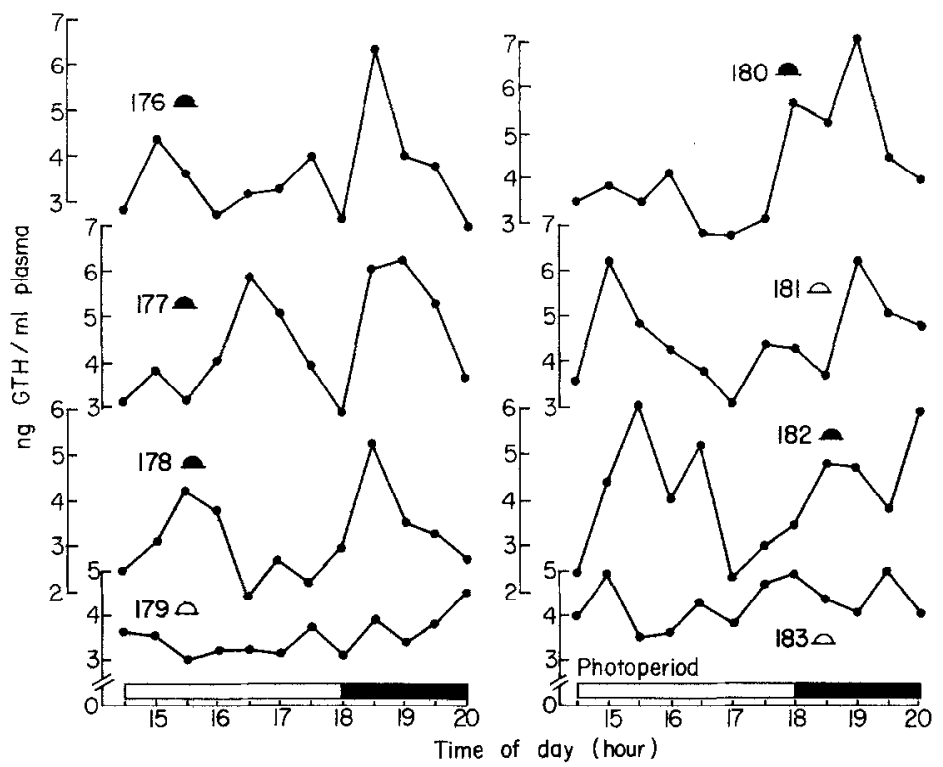

FIG. 7. Individual profiles of plasma GtH levels in female trout at advanced exogenous vitellogenesis (October). Females were bled every $30 \mathrm{~min}$ over a period of $5 \frac{1}{2} \mathrm{hr}$, between 1430 and $2000 \mathrm{hr}$. For other details, see the legend of Fig. 1.

sideration might indicate that the period during which the high-amplitude GtH pulses occur in each female is short, and that they characterize a precise given physiological state. A low degree of physiological synchronization among the studied fish might explain the differences found in their individual GtH profiles.

According to Van den Hurk and Peute (1979) and Breton et al. (1983, 1985), exogenous vitellogenesis in the rainbow trout (as observed histologically) first occurs in May, 1 to 2 months following the spring GtH rise (March). However, a recent study of the same species (Sumpter et al., 1984) has indicated that exogenous vitellogenesis can begin as early as March. Although Lambert et al. (1978), Whitehead et al. (1978a, b), Scott et al. (1980), and Van Bohemen and Lambert (1981) found very low and constant $E_{2} 17 \beta$ and vitellogenin levels in the female trout during spring, other studies have shown a slow increase in plasma $E_{2} 17 \beta$ levels starting in March (Billard et al., 1978; Breton et al., 1983) or even earlier (Fostier and Le Bail, unpublished data; Sumpter et al., 1984). Sumpter et al. (1984) reported an increase in circulating vitellogenin levels in the rainbow trout as early as January, and the beginning of its incorporation in late March. In the present study, the first signs of vitellogenin uptake were also histologically visible in the fish bled in March, in which the highamplitude GtH pulses were found. These considerations indicate that the GtH pulses might play a role in the induction of vitellogenin uptake by the follicles. In fact, Breton and Derrien-Guimard (1983) have demonstrated that physiological GtH pulses stimulate vitellogenin incorporation into in vitro perifused oocytes of rainbow trout. However, our data, showing that $E_{2} 17 \beta$ levels in fish exhibiting high-amplitude GtH pulses were constant, do not necessarily mean that GtH pulses do not play a role in controlling the synthesis and/or secretion of $E_{2} 17 \beta$ from follicles at this time of the year. In a separate study, we have demonstrated that the administration of 
physiological $\mathrm{GtH}$ pulses to in vitro perifused ovarian fragments undergoing early recrudescence stimulated their $\mathrm{E}_{2} 17 \beta$ output considerably (Zohar et al., 1982b; Zohar, Fostier, and Breton, unpublished results). In vivo, the GtH pulses might maintain constant $E_{2} 17 \beta$ levels over short periods.

The exact role of the pituitary in the control of the different phases of oogenesis has not yet been satisfactorily defined. Whereas the previtellogenic growth of oocytes seems to be independent of the pituitary (Vivien, 1939; Barr, 1963; Yamazaki, 1965), it has been shown in various teleost species that oogonial proliferation (Barr, 1963; Yamazaki, 1965) and vitellogenesis are pituitary-dependent processes (Barr, 1963; Yamazaki, 1965; Sundararaj et al., 1972; Khoo, 1979), the last one definitely being controlled by gonadotropin (Hoar $e t$ al., 1967; Hyder, 1972; Mackay, 1973; Upadhyay et al., 1978). On the basis of these observations, we cannot exclude the possibility that the high-amplitude GtH pulses found in March might also be related to the numerous oogonial mitoses and oocyte meioses, or to endogenous vitellogenesis, which were observed in the ovaries of the studied females.

In June, when most of the ovarian follicles were in the early stages of exogenous vitellogenesis, $\mathrm{GtH}(1-3 \mathrm{ng} / \mathrm{ml})$ and $\mathrm{E}_{2} 17 \beta$ $(0.5-1.5 \mathrm{ng} / \mathrm{ml})$ levels were low and constant. In September-October, when exogenous vitellogenesis was in its advanced stages, plasma GtH levels fluctuated again. In most of the studied females, episodic, short-term GtH pulses of moderate amplitude were recorded, while basal $\mathrm{GtH}$ levels $(2.4 \pm 0.6 \mathrm{ng} / \mathrm{ml})$ were only slightly higher than those recorded in June $(1.8 \pm 0.4$ $\mathrm{ng} / \mathrm{ml}$ ). The appearance of $\mathrm{GtH}$ pulsatility during exogenous vitellogenesis was accompanied by a large increase of plasma $\mathrm{E}_{2} 17 \beta$, up to levels ranging from 6 to 30 $\mathrm{ng} / \mathrm{ml}$. At advanced exogenous vitello- genesis, individual $E_{2} 17 \beta$ profiles showed continuous and progressive variations superimposed on the abrupt GtH fluctuations. In contrast with the GtH profiles, a relative synchronization existed among the individual $E_{2} 17 \beta$ profiles. This was reflected by an average $E_{2} 17 \beta$ profile showing regular significant daily fluctuations (Fig. 6). $\mathrm{E}_{2} 17 \beta$ levels increased during the photophase and reached maxima toward and during early scotophase; a decrease later on might occur, which should be confirmed.

In the goldfish, Hontela and Peter (1978) found constant plasma GtH levels in "regressed" fish, in which oocytes undergoing endogenous vitellogenesis dominated the ovary. Daily fluctuations in GtH levels appeared later on, in "maturing" and in "mature" females. In the ovaries of these females, the proportion of oocytes undergoing advanced stages of vitellogenesis was high. In all groups, basal GtH levels were the same. Based on these results, Hontela and Peter (1978) and Peter (1981) suggested that the daily fluctuations in $\mathrm{GtH}$ levels might be more important for the stimulation and the maintenance of the ovarian activity than the progressive long-term changes in the concentrations of the hormone. On the basis of our present results, a similar hypothesis might be proposed for the female rainbow trout. Whereas previous studies suggested that the important increase in circulating $E_{2} 17 \beta$ during exogenous vitellogenesis is accompanied either by a moderate increase or continuous decrease in the mean plasma GtH levels or by constant concentrations of the hormone (see introduction), our study suggests an important change in the short-term GtH profiles during the same processes. The constant levels of $\mathrm{GtH}$ characterizing the beginning of exogenous vitellogenesis become pulsatile in its advanced stages, while $\mathrm{E}_{2} 17 \beta$ increases drastically. The basal $\mathrm{GtH}$ levels remain low in both cases. This sug- 
gests that in the female rainbow trout the appearance of $\mathrm{GtH}$ pulsatility during cxogenous vitellogenesis, rather than a change in the hormone absolute levels, is responsible for the marked $E_{2} 17 \beta$ increase. However, the rainbow trout model might be more complicated than the goldfish one. The results obtained by Hontela and Peter (1978), and confirmed by Hontela and Peter (1980a, b) and Gillet et al. (1981), indicate that there is a relative synchronization between the individual GtH profiles of different females. This fact results in the detection of a significant daily cycle in $\mathrm{GtH}$ levels when different groups of fish are sampled every $4 \mathrm{hr}$. Our present data demonstrate that in the female rainbow trout, the individual GtH profiles are not synchronized since the short-term increases in GtH levels occur at different times in different females. Thus, the GtH fluctuations can be detected only if individual fish are sampled repeatedly. Averaging the individual $\mathrm{GtH}$ profiles masked the cxistcnce of GtII pulsatility, and resulted in stable mean $\mathrm{GtH}$ levels over the 24-hr sampling period (Fig. 6). A similar situation has been described by Pan et al. (1980) in three carp species; when individual $\mathrm{GtH}$ profiles were recorded during the spawning season, short-term GtH pulses were observed. As in the case of the rainbow trout at advanced exogenous vitellogenesis, those profiles were relatively nonsynchronized among individual fish.

Although it is difficult to determine the frequency of GtH pulses during advanced exogenous vitellogenesis, we observed up to $5 \mathrm{GtH}$ pulses within a 12 -hr period when the bleeding interval was $1 \mathrm{hr}$. However, the number of pulses varied between the females, and in some of them GtH levels were quite constant. This might reflect a lack of total physiological synchronization among the studied females or might be the result of not bleeding frequently enough in relation to the duration of the pulses. In many of the profiles for which bleeding was done at 1-hr intervals, a pulse included only one value of high GtH level. The pulses were longer in a few cases, and in one female (Fig. 5, No. 154) the increase in GtH levels lasted a few hours. This last example might reflect the initiation of an increase in the basal GtH levels, related to a possible initiation of the germinal vesicle migration (see Zohar et al., 1986). When the sampling interval was reduced to 30 min, most of the GtH pulses included more than one value of high GtH level. Considered together, all of the GtH profiles characterizing exogenous vitellogenesis indicate a pulse duration of 1 to $3 \mathrm{hr}$. Bleeding fish at even higher frequencies than that reported here is necessary for a precise analysis of the dynamics of the $\mathrm{GtH}$ pulses. Our present data do not demonstrate a clear circadian rhythmicity in $\mathrm{GtH}$ levels at advanced exogenous vitellogenesis. However, they indicate a possible decrease in the frequency of the $\mathrm{GtH}$ pulses during the night, which should be further confirmed.

The relationship between the $\mathrm{GtH}$ and $\mathrm{E}_{2} 17 \beta$ secretion patterns in the female trout at advanced exogenous vitellogenesis cannot be precisely determined on the basis of the present in vivo study. They arc considered in more detail elsewhere (Zohar, Fostier, and Breton, in preparation), taking into account the results of both in vivo and in vitro studies. However, the relationship between the $\mathrm{GtH}$ and $E_{2} 17 \beta$ secretion patterns differs from that described in most mammalian species, in which pulses are considered as basic signals at both the pituitary and the gonadal level. A pulsation of $\mathrm{LH}$ is immediately followed by a pulsation of a corresponding gonadal steroid in the mouse (Desjardins, 1981), the rabbit (Moor and Younglai, 1975), the goat (Muduuli et al., 1979), the dog (De Palatis et al., 1978), the ewe (Baird, 1978), the ram (Lincoln, 1976), the rhesus monkey (Steiner et al., 1980), and 
man (Backstrom et al., 1982). In the female rainbow trout, however, the short-term $\mathrm{GtH}$ pulses are accompanied by regular $E_{2} 17 \beta$ variations of longer duration. The same phenomenon was also observed in vitro (Zohar et al., 1982b and unpublished data). The greater abundance of $\mathrm{GtH}$ pulses during the day may indicate the importance of their frequency in the regulation of the progressive increase in $E_{2} 17 \beta$ levels during the photophase, as well as in the possible decrease of these levels later on.

Recently, the physiological function of fish gonadotropin(s) in relation to vitellogenesis has been a matter of discussion (e.g., Idler, 1982; Idler and Ng, 1983; Burzawa-Gerard, 1982). In this discussion, references have been made to results which are related to the circulating levels of the glycoproteic GtH. Our present study is the first to demonstrate that in the female rainbow trout, changes in the short-term secretion pattern of $\mathrm{GtH}$ occur from early ovarian recrudescence and throughout vitellogenesis, in addition to the seasonal evolution of the hormone level. Such short-term secretion patterns should be considered when the glycoproteic $\mathrm{GtH}$ role in vitellogenesis is discussed.

\section{ACKNOWLEDGMENTS}

We thank Aline Solari for her valuable help in the statistical analysis of our data, and Elisabeth Sambrony and Odile Marcuzzi for their technical assistance. This work was supported by a grant from the "Yad Hanadiv" Foundation to Y.Z.

\section{REFERENCES}

Backstrom, C. T., McNeilly, A. S., Leask, R. M., and Baird, D. T. (1982). Pulsatile secretion of LH, FSH, prolactin, oestradiol and progesterone during the human menstrual cycle. Clin. Endocrinol. 17, 29-42.

Baird, D. T. (1978). Pulsatile secretion of $\mathrm{LH}$ and ovarian estradiol during the follicular phase of the sheep estruous cycle. Biol. Reprod. 18, 359-364.

Barr, G. D., and Barraclough, C. A. (1978). Temporal changes in medial basal hypothalamic LH-RH correlated with plasma LH during the rat estrous cycle and following electrochemical stimulation of the medial preoptic area in pentobarbitaltreatcd proestrous rats. Brain Res. 148, 413-423.

Barr, W. A. (1963). The endocrine control of the sexual cycle in the plaice, Pleuronectes platessa. II. The endocrine control of oogenesis. Gepi. Comp. Endocrinol. 3, 205-215.

Billard, R., and Breton, B. (1978). Rhythms of reproduction in teleost fish. In "Rhythmic Activity of Fishes" (J. E. Thorpe, ed.), pp. 31-53. Academic Press, London/New York.

Billard, R., Breton, B., Fostier, A., and Weil, C. (1978). Endocrine control of the teleost reproductive cycle and its relation to external factors: Salmonid and cyprinid models. In "Comparative Endocrinology" (P. J. Gaillard and H. H. Boer, eds.), pp. 37-48. Elsevier/North Holland, Amsterdam.

Bliss, C. I. (1967). "Statistics in Biology." McGrawHill, New York.

Breton, B., and Billard, R. (1977). Effects of photoperiod and temperature on plasma gonadotropin and spermatogenesis in the rainbow trout (Salmo gairdneri R.). Ann. Biol. Anim. Biochim. Biophys. 17, 331-340.

Breton, B., and Derrien-Guimard, M. C. (1983). Actions de stimulations gonadotropes pulsatiles sur l'incorporation de vitellogenine in vitro par des follicules de Truites incubens dans un system de perifusion ouvert. C. R. Acad. Sci. (Paris) Ser. III 296, 857-860.

Breton, B., Billard, R., Jalabert, B., and Kann, G. (1972). Dosage radioimmunologique des gonadotropines plasmatiques chez Carassius auratus, au cours du nycthemere et pendant l'ovulation. Gen. Comp. Endocrinol. 18, 463-468.

Breton, B., Fostier, A., Zohar, Y., Le Bail, P. Y., and Billard, R. (1983). Gonadotropine glycoproteique maturante et oestradiol-17 $\beta$ pendant le cycle reproducteur chez la truite fario (Salmo trutta) femelle. Gen. Comp. Endocrinol. 49, 220-231.

Breton, B., Prunet, P., and Reinaud, P. (1978). Sexual differences in salmon gonadotropin. Ank. Biol. Anim. Biochim. Bioplys. 18(4), 759-765.

Breton, B., Zohar, Y., and Billard, R. (1985). Photoperiod and gonadotropin control of the reproductive cycle in the female rainbow trout. In "Cur" rent Trends in Comparative Endocrinology" (B. Lofts and W. N. Holmes, eds.), pp. 1243-1246. Hong Kong Univ. Press, Hong Kong.

Brinkley, H. J. (1981). Endocrine signaling and female reproduction. Biol. Reprod. 24, 22-43.

Bromage, N. R., Whitehead, C., and Breton, B. (1982a). Relationships between serum levels of gonadotropin, oestradiol-17\% and vitellogenin in the control of ovarian development in the rainbow trout. II. The effects of alterations in environ- 
mental photoperiod. Gen. Comp. Endocrinol. 47, $366-376$.

Bromage, N. R., Whitehead, C., Elliot, J., Breton, B., and Matty, A. J. (1982b). Investigations into the importance of day length on the photoperiodic control of reproduction in the female rainbow trout. In "Reproductive Physiology of Fish" (C. I. I. Richter and H. J. Th. Goos, eds.), pp. 233-236. Pudoc, Wageningen.

Bry, C., and Zohar, Y. (1980). Dorsal aorta catheterization in rainbow trout (Salmo gairdneri). II. Glucocorticoid levels, hematological data and resumption of feeding for five days after surgery. Reprod. Nutr. Dev. 20, 1825-1834.

Burzawa-Gerard, E. (1982). Existe-t-il plusieurs gonadotropines $(\mathrm{GtH})$ chez les poissons? Donnees biochimiques et vitellogenese exogene. In "Reproductive Physiology of Fish" (C. J. J. Richter and H. J. Th. Goos, eds.), pp. 19-22. Pudoc, Wageningen.

Crim, L. W., and Idler, D. R. (1978). Plasma gonadotropin, estradiol, and vitellogenin and gonad phosvitin levels in relation to the seasonal reproductive cycles of female brown trout. Ann. Biol. Anim. Biochim. Biophys. 18, 1001-1005.

De Palatis, L., Moore, J., and Falvo, R. E. (1978). Plasma concentrations of testosterone and $\mathbf{L H}$ in the male dog. J. Reprod. Fertil. 52, 201-207.

Desjardins, C. (1981). Endocrine signaling and male reproduction. Biol. Reprod. 24, 1-21.

Dixon, W. J. (1953). Processing data for outliers. Biometrics 9, 74-89.

Fostier, A., and Jalabert, B. (1982). Physiological basis of practical means to inducc ovulation in fish. In "Reproductive Physiology of Fish" (C. J. J. Richter and H. J. Th. Goos, eds.), pp. 164-173. Pudoc, Wageningen.

Fostier, A., Billard, R., Breton, B., Legendre, M., and Marlot, S. (1982). Plasma 11-oxo-testosterone and gonadotropin during the beginning of spermiation in rainbow trout Salmo gairdneri $\mathrm{R}$. Gen. Comp. Endocrinol. 46, 428-434.

Fostier, A., Breton, B., Jalabert, B., and Marcuzzi, O. (1981). Evolution des niveaux plasmatiques de la gonadotropine glycoproteique et de la $17 \alpha$-hydroxy-20ß-dihydroprogesterone au cours de la maturation et de l'ovulation chez la truite arc-enciel, (Salmo gairdneri). C. R. Acad. Sci. (Paris) Ser. III 293, 817-820.

Fostier, A., Weil, C., Terqui, M., Breton, B., and Jalabert, B. (1978). Plasma estradiol-17 $\beta$ and gonadotropin during ovulation in rainbow trout (Salmo gairdneri R.). Ann. Biol. Anim. Biochim. Biophys. 18, 929-936.
Gillet, C., and Billard, R. (1981). Effets de la temperature, de la photoperiode et des niveaux alimentaires sur la gonadotropine plasmatique et hypophysaire et la gametogenese du poisson rouge. Cah. Lab. Montereau. 11, 41-48.

Gillet, C., Billard, R., and Breton, B. (1981). La reproduction du poisson rouge (Carassius auratus) eleve at $30^{\circ} \mathrm{C}$ : Effet de la photoperiode, de l'alimentation et de l'oxygenation. Cah. Lab. Montereau. 11, 49-56.

Grubbs, F. E. (1969). Procedures for detecting outlying observations in samples. Technometrics 11, $1-21$.

Hanyu, I., and Tamura, T. (1978). Electroretinograms and spectral sensitivity in the ayu, a salmonid fish. Bull. Japan. Soc. Sci. Fish. 44, 401-406.

Hoar, W. S., Wiebe, J., and Hui Wai, E. (1967). Inhibition of the pituitary gonadotropic activity of fishes by a dithiocarbamoylhydrazine derivative. Gen. Comp. Endocrinol. 8, 101-109.

Hontela, A., and Peter, R. E. (1978). Daily cycles in serum gonadotropin levels in the goldfish: Effects of photoperiod, temperature, and sexual condi tion. Canad. J. Zool. 56, 2430-2442.

Hontela, A., and Peter, R. E. (1980a). Effects of pincalcctomy, blinding, and sexual condition on serum gonadotropin levels in the goldfish. Gen. Comp. Endocrinol. 40, 168-179.

Hontela, A., and Peter, R. E. (1980b). Synchronization of daily gonadotropin cycles with temperature, feeding, and light in the goldfish. Amer. Zool. 20, 728.

Hyder, M. (1972). Endocrine regulation of reproduction in Tilapia. Gen. Comp. Endocrinol. 3, (suppl.), 729-740.

Idler, D. R. (1982). Some perspectives on fish gonadotropins. In "Reproductive Physiology of Fish" (C. J. J. Richter and H. J. Th. Goos, eds.), pp. 4-13. Pudoc, Wageningen.

Idler, D. R., and Ng, T. B. (1983). Teleost gonadotropins: isolation, biochemistry and function. In "Fish Physiology" (W. S. Hoar, D. J. Randall, and E. M. Donaldson, eds.), pp. 187-221. Academic Press, New York.

Khoo, K. H. (1979). The histochemistry and endocrine control of vitellogenesis in goldfish ovaries. Canad. J. Zool. 57, 617-626.

Knobil, E. (1980). The neuroendocrine control of the menstrual cycle. Rec. Prog. Horm. Res. 36, $53-88$.

Lamba, V. J., Goswami, S. V., and Sundararaj, B. I. (1983). Circannual and circadian variations in plasma levels of steroids (cortisol, estradiol-17 $\beta$, estrone, and testosterone) correlated with the an- 
nual gonadal cycle in the catfish, Heteropneustes fossilis (Bloch). Gen. Comp. Endocrinol. 50, 205-225.

Lambert, J. G. D., Bosman, G. I. C. G. M., Van den Hurk, R., and Van Qordt, P. G. W. J. (1978). Annual cycle of plasma oestradiol-17 $\beta$ in the female trout (Salmo gairdneri). Ann. Biol. Anim. Biochim. Biophys. 18, 923-927.

Lincoln, G. A. (1976). Seasonal variation in the episodic secretion of luteinizing hormone and testosterone in the ram. J. Endocrinol. 69, 213-226.

Lincoln, G. A., and Short, R. V. (1980). Seasonal breeding: Nature's contraceptive. Recent Prog. Horm. Res. 36, 1-52.

Mackay, N. J. (1973). The effects of gonadotropin preparations and steroid hormones on the ovaries of intact and gonadotropin deprived Gudgeons (Hypseleotris galii). Gen. Comp. Endocrinol. 21, $278-286$.

Moor, B. C., and Younglai, E. V. (1975). Variations in peripheral levels of $\mathrm{LH}$ and testosterone in adult male rabbits. J. Reprod. Fertil. 42, 259-266.

Muduuli, D. S., Sanford, L. M., Palmer, W. M., and Howland, B. E. (1979). Secretory patterns and circadian and seasonal changes in luteinizing hormone, follicle stimulating hormone, prolactin and testosterone in the male pygmy goat. J. Anim. Sci. 49, 543-553.

Pan, J., Wang, R., Shen, R., Xu, G., Pao, X., and Xu, W. (1980). On the mode of pituitary gonadotropin releasing in carps. $J$. Fish China 4, 121-127.

Peter, R. E. (1981). Gonadotropin secretion during reproductive cycles in teleosts: Influences of environmental factors. Gen. Comp. Endocrinol. 45, 294-305.

Scott, A. P., and Sumpter, J. P. (1983). A comparison of the female reproductive cycles of autumnspawning and winter-spawning strains of rainbow trout (Salmo gairdneri Richardson). Gen. Comp. Endocrinol. 52, 79-85.

Scott, A. P., Bye, Г. J., and Baynes, S. M. (1980). Seasonal variations in sex steroids of female rainbow trout (Salmo gairdneri). J. Fish. Biol. 17, 587- 592 .

Steiner, R. A., Peterson, A. P., Yu, J. Y. L., Conner, H., Gilbert, M., Terpenning, B., and Bremmer, W. (1980). Ultradian luteinizing hormone and testosterone rhythms in the adult male monkey, (Macaca fascicularis). Endocrinology 107, 1489-1493.

Sumpter, J. P., Scott, A. P., Baynes, S. M., and Withames, P. R. (1984). Early stages of the reproductive cycle in virgin female rainbow trout (Salmo gairdneri Richardson). Aquaculture 43, 235-242.
Sundararaj, B. I., Anand, T. C., and Donaldson, F. M. (1972). Effects of partially purified salmon pituitary gonadotropin on ovarian maintenance, ovulation, and vitellogenesis in the hypophysectomized catfish (Heteropneustes fossilis) (Bloch). Gen. Comp. Endocrinol. 18, 102-114.

Upadhyay, S. N., Breton, B., and Billard, R. (1978). Ultrastructural studies on experimentally induced vitellogenesis in juvenile rainbow trout (Salmo gairdneri R.). Ann. Biol. Anim. Biochim. Biophys. 18, 1019-1025.

Van Bohemen, Ch.G., and Lambert, J. G. D. (1981). Estrogen synthesis in relation to estrone, estradiol, and vitellogenin plasma levels during the reproductive cycle of the female rainbow trout (Salmo gairdneri). Gen. Comp. Endocrinol. 45, 105-114.

Van den Hurk, R., and Peute, J. (1979). Cyclic changes in the ovary of the rainbow trout, ( 5 almo gairdneri), with special reference to sites of steroidogenesis. Cell. Tissue Res. 199, 289-306.

Vivien, J. H. (1939). Role de l'hypophyse dans le determinisme du cycle genital femelle d'un teleosteen, (Gobius paganellis). C. R. Hebd. Seances Acad. Sci. 207, 948-949.

Vodicnik, M. J., Kral, R. E., and De Vlaming, V. L. (1978). The effects of pinealectomy on pituitary and plasma gonadotropin levels in Carassius auratus exposed to various photoperiod-temperature regimes. J. Fish. Biol. 12, 187-196.

Whitehead, C., Bromage, N. R., and Breton, B. (1983). Changes in serum levels of gonadotropin, oestradiol $17 \beta$ and vitellogenin during the first and subsequent reproductive cycle of female rainbow trout. Aquaculture 4, 317-326.

Whitehead, C., Bromage, N. R., and Forster, I. R. M. (1978a). Seasonal changes in reproductive function of the rainbow trout (Salmo gairdneri). $J$. Fish. Biol. 12, 601-608.

Whitehead, C., Bromage, N. R., Forster, J. R. M., and Matty, A. J. (1978b). The effects of alterations in photoperiod on ovarian development and spawning time in the rainbow trout (Salino gairdneri). Ann. Biol. Anim, Biochim. Biophys. 18, 1035-1043.

Yamazaki, F. (1965). Endocrinological studics on the reproduction of the female goldfish, Carassins auratus $L$., with special reference to the function of the pituitary gland. Mem. Fac. Fish. Hokkaido Univ. 13, 1-64.

Zohar, Y. (1980). Dorsal aorta catheterization in rainbow trout (Salmo gairdneri). I. Its validity in the study of blood gonadotropin patterns. Reprod. Nutr. Dev. 20, 1811-1823. 
Zohar, Y., Breton, B., and Billard, R. (1982a). Shortterm profiles of plasma gonadotropin levels in the female rainbow trout throughout the reproductive cycle. Gen. Comp. Endocrinol. 46, 369.

Zohar, Y., Breton, B., and Fostier, A. (1982b). Gonadotropic function during the reproductive cycle of the female rainbow trout, Salmo gairdneri, in relation to ovarian steroid secretion: In vivo and in vitro studies. In "Reproductive Physiology of Fish" (C. J. J. Richter and H. J. Th. Goos, eds.), pp. 14-18. Pudoc, Wageningen.

Zohar, Y., Breton, B., and Fostier, A. (1986). Shortterm profiles of plasma gonadotropin and $17 \alpha$-hydroxy-20 $\beta$-dihydroprogesterone levels in the female rainbow trout at the periovulatory period. Gen. Comp. Endocrinol. 64, 189-198. 